\title{
Modernization and Psycho-Social Factors of Dementia: Special Requirements for Older People
}

\author{
Meharin Jerin Suzan \\ Institute of Social Welfare and Research, University of Dhaka
}

\begin{abstract}
This study is conducted among the older people with dementia who are affected by modernization. This is based on broad objectives of exploring the psycho-social factors of older people with dementia and which is related to the modernization. This study has been followed qualitative research approach and for this purpose it selected six cases from Bangladesh. Case study method, purposive sampling technique and semi-structured interview schedule have been used to collect data. The findings of the study has been showed that the on-going process of forming nuclear family will add more pressure on the elderly support system because of modernization. This changing situation is created different kinds of diseases like dementia. Most of the demented people are 60 and over 60 years old. All of them are suffering other diseases like diabetics, high blood pressure, depression, anxiety and so on. This study also reveals that the course of dementia differ from person to person and is associated with a range of factors including the subtype of dementia, physical health issues, lifestyle aspects and the social support systems of the person with disease. It is observed that they are not aware about their rights and opportunities. Participants haven't got proper medical facilities to cure this disease. This work will also strive to ensure the facilities of the older people with dementia so that they will maintain their social status. This work will be also ensured the facilities of the dementia for the older people.
\end{abstract}

Key Words: Older People, Dementia, Modernization Modernization and Psycho-Social Factors of Dementia: Special Requirements for Older People

\section{INTRODUCTION}

$\mathrm{T}$ he world's population is increasing out of control. Bangladesh, the eighth largest (147.3 million in 2008) and one of the most densely populated countries (966 persons per sq. km. in 2007; BBS, 2008) in the world. Population ageing is an emerging issue and new experience in the world that are vulnerable in the development context. Elderly aged is the closing period of time in the life cycles. In this time attitudes against life, person's activities, biological capacities, physical fitness and relationships to the family and work all are confined of the particular society where she or he lives. In the new post-industrial life, older people are isolated with great number. Society couldn't give enough facilities in this unpredictable time and this time, the life of older people has turned into fragmented, disorderly, and unpredictable. Major events of life can't get priority as a part of a predictable or natural pattern (Sultana, 2011). The population census of Bangladesh, 2011 showed that 7.4 per cent of population is older people. This percentage of elderly population has been projected to increase 8.0 per cent in $2020,11.9$ per cent in
2035 and 17.0 per cent in 2050.Demographically, growing rate of older people is a global phenomenon and Bangladesh is also not exceptional by this demographic reality. The pattern of life is changing because kinship bonds are weakening and family composition is being changed due to modernization (Rahman and Nasrin, 2012).

The term modernization came into popular use after World War II. It is an interrelated process that agrarian, rural societies turned into modern societies (Encyclopaedia, 2017). In the process of urbanization, most of the young family members leave their older family members in rural areas. The new family form in modern society is nuclear family. Both social and spatial distances have been increased in the young and the aged people due to change in intergenerational relations. As a result aged people are distressing from many mental health problems such as dementia.

Dementia is a rising health concern in the world. The increasing growth of longevity and decreasing growth of fertility rates are responsible to shift the age of distribution of populations towards older age groups in many parts of the world, especially in industrialized countries. Healthcare services, medical technology, improved sanitation as well as increased individual wealth all are contributing to increase the life expectancy. At a recent time older people are affected by so many unknown diseases as well as older people affected the non-communicable diseases like dementia. After conducting this research it is realized that there are no specific health care center or non-government facilities towards dementia patient. Sometimes, some facilities are being provided among the dementia patient but in developing countries like in Bangladesh, facilities are very poor. Most of the people have no knowledge about dementia in this country. Families who have dementia person they have no idea how to take care and how to handle people with dementia. Government and non-government agency should arrange seminar, symposium about dementia to raise awareness among the people.

\section{Rationality of the Study}

At present, the number of the elderly people in Bangladesh is 9.41 million, which is larger than the national population of many countries of the world (Khan, 2011). The growing rate of population aging is now worldwide and flows freely into social and economic support system, which is influenced by the changing and common era in the age structure. In the side of Bangladesh, rapid urbanization, mass poverty, rapid 
socioeconomic and demographic transformation, decline social and religious values, the influence of western and modern culture and other these types of factors are responsible for bearing the nuclear family.

Elderly people used to enjoy respectable, happily, honorable life in the past in the traditional joint family or extended family system of the country. But this family pattern have been changed due to upcoming nuclear family pattern, urbanization, migration economic hand ship, decline social values and other factors. This changing situation of socioeconomic condition is causing to the life of elderly very difficult and so pathetic. Aloneness is only company in every moment. They suffer from various diseases and mental problems; like that dementia is one of them.

Caring is being challenged for the older people with dementia. The progressive degeneration of the person's cognitive capacity is being reduced so that reducing ability to communicate and to undertake daily activities is a common scenario. It is also often associated with behavioral and psychological changes of dementia that can be difficult to respond to.

As a consequence, there are often serious social and health of patients of dementia. Social impact includes reducing the work hours or loss of employment, loss of relationships, time with friends and families and social activities. Negative aspects of mental health such as depression, anxiety, stress, physical problems and sleep disruption have been seen among the older people with dementia. Family members of people with dementia have additional stresses to take care of them. Older people with dementia are particularly vulnerable to the risk of abuse and neglect.

Most of the family members rough behaved to them. In view of this impact of modernization concerned with the older people who are affected by dementia, a need for social investigation with a view to understanding present condition of them has strongly been felt. This study has been conducted to take some other fruitful measures. Through this study two advantages may be ensured, one is to introduce impact of modernization on older people which is related to the psychosocial factors of dementia and other is services requiring to older people with dementia. This study hopefully will be pertinent sources of information for those who will be interested in caring out further research in this field.

The proposed study however will make an attempt to gather information out of which the planners can make their own assumption of the prevailing situation. A matter of fact this study will contribute to the knowledge of the policy makers, planners to draw up a more realistic and appropriate social policy and programs for the betterment of this problem of older people. Finally this study will help researcher pave the way for further researcher on new dimension and directions of the old age problem.

\section{Objectives}

The general objective of the study is to find out the psychosocial factors of dementia which is mostly related with modernization and requirements of older people in this context. To understand the general objective some specific objectives are taken in this study. They are as follows:

- To know the demographic condition of the older people with dementia;

- To explore the psycho-social problems of demented older people;

- To know the need of the older people with dementia;

- To investigate the negative impacts of modernization on older people with dementia;

- To identify the existing services for dementia with older people;

- To identify the needs of older people with dementia and recommend with special reference to dementia care.

\section{METHODOLOGY OF THE STUDY}

To address the research aim and objectives of the study, qualitative approach has been selected because qualitative data is richer and is generally grounded in a subjective perspective. Case study method has been used as a main method to conduct this research.

The part of different areas prioritizing Bangabandhu Sheikh Mujib Medical University (BSMMU), Dhaka Medical College Hospital, Bangladesh Association for the Aged and Institute of Geriatric Medicine (BAAIGM), others different hospitals, old home of Dhaka city of Bangladesh have been selected as areas of this present study. In the research area, all the older people of age group 60 and above with dementia have been considered as population for this study and each of them have been considered as unit of analysis. Purposive technique is applied to select the sample of the study so that respondents have expressed their opinion in an easy way. Purposive sampling has been used to apprentice the respondents so that they could provide in-depth and detailed information which was needed for research. It is highly subjective and determined criteria which have helped to collect data from the participants. From both primary and secondary sources, data is being collected. Source of primary data is the respondents (older people with dementia). A semi-structured interview schedule has been prepared for data collection. It is a close and open ended interview schedule. Observation techniques have been applied to collect data from respondents. Their verbal expression and emotional status have been also observed on that time of interview.

The source of secondary data is research paper, daily newspaper, web information, government reports, and official statistics, different national and international journals which are relevant to dementia with older people. To conduct the present study, semi structured interview schedule was very useful methods to keep the interviewers thought on a particular way as it helps to express the conceptions on the 
particular topic in more detail. It was the most suitable method for answering the research questions in this particular topic. It has allowed focused, conversational, two-way communication and to receive reliable, comparable qualitative data. According to concept of the study and themes of the study, data have been analyzed. Recorded words were written out to understand the respondent's exact and actual view. Obtained information was organized in different ways according to the objectives.

\section{FINDINGS OF THE STUDY}

Bangladesh is going through a phase of rapid demographic aging. Elderly people are suffering many illnesses such as dementia is a new era in the world. It declined the cognitive abilities like decision making, thinking and learning abilities. Now it is an international issue. Gradually, this issue became prominent and come to the forefront from behind the screen. The more the society is developed the more focus on such issues are became get preference. For effective analysis have been designed two categories of the collected information. One category is problems which are faced by respondents who are affected by psycho-social factors of dementia and modernization.

\section{Problems of Older People with Dementia}

Problems are many among the older people with dementia. Respondents of this study are not except from others. These are given below:

\section{Affected by Chronic Diseases and Indigenous Tradition}

Most of the respondents were affected by other diseases like diabetes, heart diseases, back pain, cardiovascular disease, high cholesterol or bad habits like physical inactivity, taking junk food, smoking and so on. These diseases and bad habits were increasing risk of dementia. Especially diabetes and hypertension have contributed to affect by dementia. High blood pressure is increasing the risk of dementia also.

\section{Shortage of Health and Other Services}

Most of the respondents wanted to diagnosis by a doctor but there is no trained and experienced doctor of the dementia. There are shortages of specialists' doctor of the dementia patient. Respondents and their families' haven't any seriousness to show the doctor to identify the physical problems. Respondents and their families thought that he or she have no severe sign of physical deterioration of the dementia. Difficulties of service delivery are existed among the patient of dementia people because of acute metal problems.

\section{Lack of Communication Skills for Health Care Professionals}

There are no trained professional caregivers of the respondents of this study. Care giver has no idea how to handle this type of patients. They have no professional knowledge of the take care of dementia patient.

\section{Misperception with Time or Place}

Most of the respondents cannot memorize the dates, time, name of the months. Respondents face any matter of understanding in time. Sometimes they forget where they live or how they go there.

\section{Problems to Understand the Pictorial Things}

Most of the respondents have determined the colour. He or she cannot identify the colour combination. Sometimes respondents of this study passed away in the mirror but cannot identify of him. They cannot understand the place distance and unable to take decision.

\section{Trouble with words in Speaking or Writing}

Participants of this study cannot continue conversation. If someone talked with them they usually have to stop in the middle of conversation, it's like a habit. They cannot memorize the word to use their conversation. Most of the respondents forgot how to read and write.

\section{Removal from Work or Social Actions}

Most of them are started to change their behavior. They left their work and social engagements. Even they cannot practice their hobbies. Sometimes they have to face uninterested feeling in family or social obligations.

\section{Variations in Mood and Character}

Participants have personality alteration problems because always they have confusion, depression, suspicion. They sat in their room with disappointed mood.

\section{More Treatment Cost}

Participants of this study have affected by many diseases. For these diseases, they need proper treatment as long term procedure. More treatment cost is needed for long term disease. As a demented people they need also extra care like nursing care. They need also good food. But due to economic condition they cannot bear the more treatment cost.

\section{Difficulties in Resolving Problems and Developing Plan}

Most of the respondents do not develop a plan to complete their any tasks. Even they cannot solve their own small problems and they cannot give concentration than before on any activities.

\section{Trouble with Complete Accustomed Tasks at Home, at Work}

Most of the respondents cannot do their daily activities. They forget the rules of their favorite game and forget to manage the budget. They need help to use microwave or memorize the favorite television show.

\section{Unable to Memorize and Down the Capacity to Repeat Stages}

Respondents always forget where he or she kept their daily necessary things. They cannot search properly to get back their things. Sometimes with unawareness mind he or she steals others things. 


\section{Poor Judgment}

Most of them cannot take decision properly to do any type of activities. Sometimes he or she makes wrong decision. They cannot deal with financial issues properly.

\section{Depression}

Depression is an acute problem among respondents. It has been lost their memory. Depression is being helped to brain failure which is responsible for dementia. Dementia and depression can bring more complications for dementia patient. Mood of the respondents of this study is being changed, they become anxious, irritated with small matter of their family. They think negatively and they are becoming hopeless day by day. They lost their feel of appetite.

\section{Malnutrition}

Malnutrition is associated with dementia. Respondents of this study have economic problem also they cannot fulfill their daily demands. In present cases; they cannot get proper psychological support and proper treatment. They cannot maintain their rules and regulations due to lack of caregivers and irresponsible role of their family members. There is a most common problem among the cases in research is low knowledge of the dementia of the family members and relatives. Governments do not give proper treatment to the dementia people.

\section{Many Other Problems}

Many other problems include-

- Lack of regular exercise

- Lack of hygienic sleep

- Lack of balanced diet

- Cardiovascular disease

- Uncontrolled diabetes

- Uncontrolled blood pressure

- Obesity

- Smoking

- Repeated traumatic brain injuries

These are the other problems among the people with dementia.

\section{Preventive Measures (Special Requirements of Older People)}

According to aims and objectives second category is preventive measures, these are given below:

\section{Individualize Maintenance}

For any demented person, care or maintenance is first priority. Participants of this study need individualize care and family members have to give priority to provide care and help to follow the maintenance rules of treatment.

\section{Protect People from Risk of Dementia}

Respondents of this study require risk management therapy. The have to manage the vulnerable situation of them. They have to try to complete their daily task.

\section{Manage Neuropsychiatric Symptoms}

Every respondent has to manage the challenges of neuropsychiatric symptoms. They need psychotherapy to manage psychological and social problems. They need also pharmacological help to manage the neuropsychiatric.

\section{Awareness Building}

People have miss perception about dementia and they have also stigma to the demented people. People cannot accept this dementia is a condition that affected person has to maintain the rules and regulations. Doctors, professionals, caregiver have to take training to give proper treatment of the demented people. Building awareness is very important for the family members of the participants. Seminar, symposiums have to arrange more for raising awareness among the family members of the res[ondents. Publications have to increase related to dementia issues. In addition to, demented people have to conscious their legal rights to having facilities from government, communities and families.

\section{Social Isolation Need to Prevent}

Respondents have isolated due to dementia problems. In our societies, government and communities have to take steps legally to preserve their rights. Social engagement of demented people has to increase to diminish their mental problems. Familiar environment should be arranged for respondents so that they feel better. They have to always keep happy.

\section{Manage Risk Factors}

Among the demented people risk factors have to eliminate such as obesity, smoking, use of alcohol. Many physical problems which have to be eliminated like hypertension, high cholesterol and so on.

\section{Need to Proper Diagnosis}

Respondents of this study did not get diagnosis facility in proper time. They were diagnosed dementia after the required time for this they had to affect by many others diseases. Earlier diagnosis can enable my respondents to take decision about their treatment. Various therapy can be improved their condition like psychotherapy is effective for them. These therapies can be removed their cognitive impairment and improve their quality of life. But diagnosis has to be done by professional staff or trained doctor.

\section{Supervision and Carefulness}

Respondents require getting proper care and management. They have to keep themselves under supervision. Supervisor can be a caregiver or doctor or family members. Respondents have right to take support, care from government and their family members have also right to get financial support.

\section{Person-Centered Dementia Care}

Participants of this study need support to adjust their own behavior. Psychotherapy is very much needed to recover from 
this situation. To ensure their social activities, they need proper care personally.

\section{Applicable Precaution}

Respondents need follow applicable precaution. It is essential to confirm the treatment in hospital or by professional doctors or trained caregiver. One of the respondents has to face these types of problems that when he caught in illness, when he admitted in a general hospital where he couldn't find treatment facilities towards dementia. So he could not get proper treatment as he demand.

\section{Psychosocial Interventions have to Applied}

Psychosocial interventions can reduce the disability in dementia. Psychosocial interventions indicate cognitive training, cognitive stimulation, behavioral therapy and activities of daily living training. Respondents of this study need to psychosocial interventions to ensure caregivers quality of life, reduce anxiety or depressive symptoms, understanding the needs of the caregivers.

Medical, economical, emotional and social issues are responsible to vulnerable situation of demented people. It is a common phenomenon in the society. Shortages of knowledge of dementia, lack of specialists' doctor of dementia, lack of social security, excess medical cost are common challenges for demented person. Older people are experienced person so that they have enough knowledge. But people cannot accept this. So, people have to play vital role to bring their position.

\section{DISCUSSION}

Dementia is a condition that damaged the all physical and mental abilities of any person. It is an international public health issue. Globally, there are 50 (million) demented people and in 2030 its amount will be 82 (million) and in 2050 it will be 152 (million) (ADI, 2015).

Dementia is a debilitating syndrome that a great impact on individuals and societies. But there are limited services to prevent dementia. People have no knowledge how to improve their life condition. Even caregivers have no academic training to overcome the disease. Awareness level is very low to develop their condition. Depression, stress, sleeping, disturbance, obesity, diabetics other psychological problems are the main reason of affecting dementia. Specific interventions have not been introduced for recovering the demented people. Diet intervention, nutritional services, psychological exercise can control this disease. Actually there is no cure for dementia. So, people of the society as well as government should take initiative to prevent this disease. Governments have to also formulate policy, law which is relating to prevent of dementia. Plan should be implemented as well as resources should be allocated to prevent dementia as early will possible.

ADI, 2015 showed that dementia is not a curse for them but their family members have to suffer with them badly. Its treatment cost is very high. They and their caregiver have not enough knowledge to prevent this illness. Government is trying to take initiatives to formulate policy and trying to implement strategies.

Findings of this study revealed that dementia is a societal issue. It needs to address the people with dementia. Strategies and their implementation have to introduce to prevent dementia. But due to lack of awareness of people of dementia, lack of knowledge of dementia care, lack of dementia doctors, caregivers, treatment facilities are the obstacles to prevent dementia.

H. Cherknow (2018) showed that demented person has lost their intellectuality. It is being damaged the brain functions gradually by stage by stage. Memory loss is common symptom of dementia. It damaged the mental health. Sleeping problem is very much related to dementia. Public awareness, proper care, training of caregivers, psychotherapy can prevent this. Government should allocate resources to address the people of dementia.

This study showed that respondents have cognitive problems, they cannot memorize the past. Sometimes they forget their name and address they have sleep disturbance, anxiety. They haven't found any facilities to prevent their disease. Government has to introduce national dementia plan to prevent dementia.

ADI, 2014 revealed that due to urbanization, industrialization, extended families turned into nuclear families is the reason of leaving the older people in rural areas. They have to live without their sons/daughter. They are starting feel lonely. They are affected by various diseases, dementia is one of them. They are suffering from malnutrition. They need counseling and proper care as well as support. This report also showed that by health promotion, health maintenance; continue the physical exercise can prevent the dementia.

This study showed that dementia has dramatic effects on the lives of the people. It has no cure. Respondents are suffering many problems due to impact of social, economic, financial issues of dementia. Facilities are very poor to continue treatment of the people with dementia. People have no choice that they have to depend on government facilities but governments haven't enough facilities to prevent dementia.

AA, 2020 showed that dementia is an illness that damaging our mental ability. Person with dementia lost their cognitive abilities. They are always feeling fear and they are confused with every decision making. This study revealed that person with dementia has many mental problems like hallucination, delusion, and paranoia and so on. So, caregivers have to acquire deep information about how to take care and how to handle person with dementia. Maintaining healthy diet, physical exercise can prevent dementia. Caregivers have to take training to give services among the people with dementia.

This study also showed that respondents cannot do their own daily task. They have also so many mental problems. But they have no caregiver to support them properly. Even her or his 
family members don't know the services, diagnosis system and service system.

Through the discussion of above literature devastative scenario of older person with dementia has been found. Most of the respondents have same situation. At the last part of life, they are helpless in society. Older people had enjoyed more in their extended, joint family structure. They have gotten honor and respect as they demand. But present situation is being changed due to modernization and urbanization. Economic hardships, declining social values, changes of the culture are also responsible for this situation. This altering environment is being created many socio-economic and psychological problems of older people. They are suffering from various diseases like dementia. It is world-wide problem. It is the reason of changes of brain function.

Most of the demented people are 60 and above 60 years. All of them are suffering many diseases like diabetics, high blood pressure, sleeping problems, nervousness, sadness and many other physical problems. Social distance and stigma are responsible to deprived of identifying the dementia. The sign and symptoms are varied from person to person of dementia because family background, life standard are not same of the people.

\section{RECOMMENDATIONS}

Older people are increasing due to improvement treatment, raising awareness of people about health issues, availability of modern health facilities.

- Adequate support and healthcare facilities in many countries are not prepared for this disease, so adequate support and healthcare facilities should be taken to improve the challenges of dementia

- Separately dementia policy should be formulated to prevent dementia

- To give the treatment and diagnosis facilities of dementia specialized hospitals should be established

- To stimulate people to know the way to communicate with the people with dementia

- Increase the social security programmes such as pension, allowance. Government should increase the old age allowance and give the transport facilities for the older people with dementia.

\section{CONCLUSION}

There are a big number of older people who are suffering from many diseases like that dementia is one of them. Dementia is a well-known illness in the present world and ageing is a common problem in the world. Due to economic condition of the country older people can't get proper care. Women empowerment is now a common matter in the world and they are participating in all development sectors. The new form of family structure nuclear family structure is a popular. For this people are shifting in urban areas and older people are staying in rural areas. This is common scenery in the whole world like Bangladesh. It's a perfect time to include a long term policies to give the care and treatment in the old age. In five year planning this policy have to add. Preventive measures are failed to cure dementia. All of the therapy of dementia patient is expensive. It is difficult to bear them due to poor economic condition. However funding agencies are trying to provide services for demented person. But it is not enough for such a huge number of affected people. Government has taken some steps to cure dementia but this is so limited for the people with dementia.

\section{REFERENCES}

[1] Alzheimer's Association America (2020) Retrieved from https://www.alz.org.

[2] Bangladesh Bureau of Statistics (BBS) Report (2008) Statistics and Information Division (SID): Ministry of Planning Retrieved from bbs.gov.bd.

[3] Bangladesh Bureau of Statistics (BBS) Report (2007) Statistics and Information Division (SID): Ministry of Planning Retrieved from bbs.gov.bd.

[4] Hossain Md Anwar and Sultana Shahana (2016) Urbanization and Urban Population in Bangladesh The census data of 2001 and 2011 revisited: CUS bulletin on Urbanization and Development number 69 and 70 December.

[5] Khan T.A. Hafiz, Kabir Russell, Kabir Mohammad, Rahman Md Twyeafur (2013) Population Ageing in Bangladesh and its implication on Health Care: European Journal of Scientific November.

[6] Modernization (2021) Encyclopaedia Britannica Retrieved from https://www.britannica.com/topic/modernization.

[7] Nasrin Sarker, Obaida and Rahman, K M Mustafizur (2009) Factors Affecting Early Marriage and Early Conception of Women A Case of Slum Areas in Rajshahi City Bangladesh: International Journal of Sociology and Anthropology.

[8] World Health Organization (2014) Global Health Observatory Retrieved from http://apps.who.int/gho/data/node.country. 